\title{
Long-term visual outcomes and patient satisfaction following bilateral implantation of trifocal intraocular lenses
}

This article was published in the following Dove Press journal:

Clinical Ophthalmology

9 August 2017

Number of times this article has been viewed

\section{Sri Ganesh \\ Sheetal Brar \\ Archana Pawar}

Nethradhama Superspeciality Eye Hospital, Bangalore, Karnataka, India
Correspondence: Sheetal Brar Nethradhama Superspeciality Eye Hospital, 256/I4, Kanakapura Main Road, 7th Block, Jayanagar, Bangalore 560082 .

Karnataka, India

Tel +9l 9591002092

Email brar_sheetal@yahoo.co.in
Purpose: To study the long-term visual and refractive outcomes and evaluate patient satisfaction after bilateral implantation of trifocal intraocular lenses (IOLs).

Setting: Nethradhama Superspeciality Eye Hospital, Bangalore.

Design: Prospective, nonrandomized study.

Methods: Eligible patients undergoing bilateral phacoemulsification with trifocal IOL implantation were included. Follow-up examinations were conducted at day 1, 1 week, 1 month, 6 months, and 12 months. Postoperatively, 1 month onward evaluation of uncorrected and distance-corrected far and near visual acuity; reading acuity and reading speeds (using Salzburg Reading Desk) at 70, 80 , and $90 \mathrm{~cm}$; contrast sensitivity; defocus curves; and patient satisfaction was carried out.

Results: Fifty eyes from 25 patients with a mean age of $58 \pm 13.44$ years were included. All eyes showed significant improvement in spherical equivalent, uncorrected distance visual acuity, corrected distance visual acuity, uncorrected near visual acuity, and corrected near visual acuity at 1 month compared to preoperative values $(P<0.05)$, with no significant change in these parameters thereafter until the last follow-up $(P>0.05)$. At 12 months, mean uncorrected reading acuities and reading speeds at 70,80 , and $90 \mathrm{~cm}$ were in the range of $0.09-0.04 \log \mathrm{MAR}$ units and 153.6-169.0 words per minute, respectively, with significantly better results at $80 \mathrm{~cm}$. Five eyes underwent YAG laser capsulotomy for early posterior capsule opacification (PCO) at a mean follow-up of 7.2 \pm 2.9 months. Contrast sensitivity scores at 12 months were comparable to 1 month ( $P>0.05$ for all spatial frequencies). All patients reported good tolerance and $100 \%$ independence from spectacles for all activities.

Conclusion: Trifocal IOLs provided excellent unaided vision at all distances. Reading performance was good through the complete intermediate distance range. PCO occurrence and subsequent YAG capsulotomy did not affect the long-term visual outcomes.

Keywords: diffractive, trifocal, salzberg reading desk, reading speeds, intermediate vision, patient satisfaction

\section{Introduction}

Recently, various multifocal intraocular lenses (IOLs) have been shown to reduce dependence on glasses after cataract surgery. ${ }^{1-4}$ These IOLs can be either refractive or diffractive in design or a combination of both. However, each of these may have potential disadvantages such as pupil dependence with refractive IOLs. ${ }^{5,6}$ However, on optical bench testing, diffractive multifocal IOLs have been shown to provide better optical quality, contrast sensitivity, and less photic phenomena than refractive IOLs. ${ }^{7,8}$

Traditional multifocal IOLs are bifocal and have two focal points for far and near distance, at which they produce a sharp image on the retina. ${ }^{2}$ The introduction of a third 
focus with the aim of providing good intermediate vision, between the two focal points, has led to the development of trifocal IOLs. Recently, the safety and efficacy of these IOLs in providing good functional vision at intermediate distance have been evaluated. ${ }^{9,10}$

The aim of the present study was to evaluate visual and refractive outcomes with the AT LISA tri 839MP or Zeiss trifocal IOL, assess reading speeds using Salzburg Reading Desk (SRD), and evaluate patient satisfaction and spectacle independence in a long-term follow-up of 1 year after surgery. ${ }^{11}$

\section{Methods}

This prospective, single-center study was approved by the hospital ethics committee of Nethradhama Superspeciality Eye Hospital and performed in accordance with the principles of the Declaration of Helsinki. All patients provided written informed consent.

Inclusion criteria were healthy eyes besides senile cataract, corneal astigmatism $\leq 0.75$ diopters (D), IOL power calculation resulting in diopters between $+10.00 \mathrm{D}$ to $+32.00 \mathrm{D}$, capsular bag IOL implantation, and ability to read English language fluently.

Exclusion criteria were patients with corneal astigmatism of $>0.75 \mathrm{D}$, irregular astigmatism, corneal dystrophy, tear-film or pupillary abnormalities, history of glaucoma or intraocular inflammation, macular disease or retinopathy, neuro-ophthalmic diseases, and intraoperative or postoperative complications.

\section{Preoperative assessment}

Preoperatively, all patients underwent a complete ophthalmologic examination including uncorrected distance visual acuity (UDVA), corrected distance visual acuity (CDVA), uncorrected near visual acuity (UNVA), distance-corrected near visual acuity (DCNVA) at $40 \mathrm{~cm}$ (all measured using logMAR acuity charts under photopic conditions at 85 candelas $[\mathrm{cd}] / \mathrm{m}^{2}$ ), manifest refraction, slit lamp biomicroscopy, noncontact tonometry, and dilated fundus examination.

\section{Description of the study lens}

AT LISA tri 839MP (Carl Zeiss Meditec, Jena, Germany) is a refractive-diffractive trifocal preloaded IOL with a $6.0 \mathrm{~mm}$ biconvex optic, an overall diameter of $11.0 \mathrm{~mm}$, and a posterior surface with asphericity of $-0.18 \mu$. It has a four-haptic design with an angulation of $0^{\circ}$ and a new $360^{\circ}$ square edge to prevent posterior capsule opacification (PCO). It is made of foldable hydrophilic acrylic material with a water content of $25 \%$, a hydrophobic surface, and a refractive index of 1.46 .
This IOL is trifocal within an IOL diameter of $4.3 \mathrm{~mm}$ and has an outer bifocal ring from 4.3 and $6 \mathrm{~mm}$. In the central $4.3 \mathrm{~mm}$ diameter, the IOL provides a near addition of $+3.33 \mathrm{D}$ and an intermediate addition of $+1.66 \mathrm{D}$, both calculated at the IOL plane. The addition power between the diameters of 4.3 and 6 $\mathrm{mm}$ is $+3.75 \mathrm{D}$ (bifocal AT LISA model). The IOL is available in spherical powers from 0.0 to $32.0 \mathrm{D}$ in 0.5 -D increments. The company-labeled A constant for this IOL is 118.6.

IOL power was calculated by using three established formulae: SRK/T, Holladay II, and Haigis. The newer generation formulae - Haigis and Holladay II - performed well across a very wide range of axial lengths. ${ }^{12}$ They were combined to calculate the IOL power in emmetropic eyes; the SRK/T was excellent for long myopic eyes, and Haigis formula for hyperopic eyes. ${ }^{13}$ The refractive target was emmetropia to $-0.25 \mathrm{D}$ in all cases. All values were obtained by using partial coherence interferometry (IOLMaster 500; Carl Zeiss Meditec AG).

\section{Surgical technique}

All surgeries were performed by a single experienced surgeon (SG) under topical anesthesia. A standardized surgical technique was employed by using a $2.8 \mathrm{~mm}$ temporal clear corneal incision. After phacoemulsification, the foldable trifocal IOL was injected in the capsular bag through a $5.5 \mathrm{~mm}$ capsulorhexis. Postoperative topical therapy included a combination of antibiotic, steroidal, and nonsteroidal antiinflammatory agents.

Postoperative examinations were performed at 1 day, 1 week, 1 month, 6 months, and 12 months and included the same tests performed as in the preoperative assessment. At every visit, $\log$ MAR acuity charts were used to evaluate distance visual acuity. Logarithmic visual acuity charts were used to assess near visual acuity at $40 \mathrm{~cm}$.

Reading performance was evaluated by using the SRD (University Eye Clinic, Paracelsus Medical University of Salzburg, Austria), which provides for controlled reading distance and automated calculation of the reading speed and logarithmic reading acuity. At each postoperative follow-up from 1 month onward, reading acuity, reading speed (speed associated with maximum reading acuity), and the smallest print size that could be read with a minimum reading speed of 80 words per minute (wpm), which represents the lower limit for recreational sense-capturing reading, were evaluated. ${ }^{14,15}$ All measurements of reading performance were performed with and without distance correction.

Contrast sensitivity was tested from 1 month onward until the last visit binocularly with distance correction under 
mesopic conditions at spatial frequencies of $1.5,3,6,12$, and 18 cycles per degree using the functional acuity contrast rest (F.A.C.T. Stereo Optical Co., Inc., Chicago, IL, USA).

Preoperatively, patients were shown pictures representing dysphotopic phenomena, specifically halos, glare, and starbursts, and were informed about their occurrence and meaning. On all postoperative visits from 1 to 12 months, the same pictures were shown and the patients were asked to classify each of these three visual symptoms according to a 5 -point scale $(0=$ no trouble; $1=$ minimal trouble $; 2=$ moderate trouble; $3=$ considerable trouble; $4=$ overwhelming trouble). Total score of all three complaints (halos, glare, and starbusts) was analyzed for each patient (maximum score $=12$, minimum $=0$ ). Also, at the same visit, all patients were asked to answer the question "Do you wear glasses or feel the need to wear glasses for activities like watching television, working on computer or reading?" They were asked to choose one of the responses - yes or no.

At the 12-month visit, the binocular defocus curve was evaluated under photopic conditions $\left(85 \mathrm{~cd} / \mathrm{m}^{2}\right)$ by using defocusing lenses from +1.00 to $-4.00 \mathrm{D}$ in $0.50 \mathrm{D}$ steps.

\section{Statistical analysis}

Statistical analysis was performed by using Excel spreadsheet software (Microsoft Corp., Redmond, WA, USA). The paired $t$-test was used to compare the mean preoperative and postoperative visual acuity. The statistical significance of any intergroup contrast sensitivity differences was assessed with a paired $t$-test at each frequency. A $P$-value of $\leq 0.05$ was considered statistically significant.

\section{Results}

The study group comprised 50 eyes from 25 patients, with a mean age of $58 \pm 13.44$ years, who underwent bilateral cataract surgery with implantation of trifocal IOL. There were $14(56 \%)$ males and 11 (44\%) females treated. All patients completed the 12-month follow-up. No eye was excluded from the analysis because of intraoperative or postoperative complications.

\section{Distance visual acuity and refraction}

Table 1 shows the postoperative visual and refractive outcomes at 1 month, 6 months, and 12 months. All patients had significant improvement in binocular UDVA and CDVA after surgery compared to preoperative values $(P<0.01)$. Postoperatively, the UDVA and CDVA did not change significantly between 1 month, 6 months, and 12 months $(P=0.07)$. Figure 1 shows the cumulative percentage of eyes with $\log$ MAR UDVA and CDVA, 12 months after the surgery, and $98 \%$ eyes $(49 / 50)$ had UDVA of $\leq 0$. The UDVA was $\leq 0.2 \log$ MAR in all $50(100 \%)$ eyes. All eyes achieved $\leq 0.1 \log$ MAR CDVA. The UNVA and DCNVA at $40 \mathrm{~cm}$ also showed similar trends and was $\leq 0.1 \log$ MAR in all 50 (100\%) eyes at 12 months (Figure 2 ).

\section{Stability of spherical equivalent (SE) refraction over time}

There was a statistically significant reduction in SE after surgery $(P<0.05)$. However, there were no statistically significant differences in SE between 1 month, 6 months, and 12 months postoperatively $(P>0.05)$ (Figure 3$)$.

Table I Distant and near visual acuity at I, 6, and I 2 months postoperatively

\begin{tabular}{|c|c|c|c|c|}
\hline Visual acuity (logMAR) & Preoperative & I month & 6 months & 12 months \\
\hline \multicolumn{5}{|l|}{ UDVA } \\
\hline Mean \pm SD & $0.30 \pm 0.25$ & $-0.014 \pm 0.08$ & $-0.006 \pm 0.087$ & $-0.012 \pm 0.055$ \\
\hline Range & $0.00-1.00$ & $(-0.10-0.10)$ & $(-0.20-0.20)$ & $(-0.20-0.20)$ \\
\hline$P$-value & & 0.00 & 0.162 & 0.371 \\
\hline \multicolumn{5}{|l|}{ CDVA } \\
\hline Mean \pm SD & $0.206 \pm 0.208$ & $-0.028 \pm 0.04$ & $-0.02 \pm 0.06$ & $-0.022 \pm 0.058$ \\
\hline Range & $0.00-0.80$ & $(-0.20-0.0)$ & $(-0.20-0.2)$ & $(-0.20-0.10)$ \\
\hline$P$-value & & 0.00 & 0.533 & 0.813 \\
\hline \multicolumn{5}{|l|}{ UNVA (40 cm) } \\
\hline Mean \pm SD & $0.25 \pm 0.186$ & $0.028 \pm 0.045$ & $0.04 \pm 0.05$ & $0.02 \pm 0.040$ \\
\hline Range & $0.10-0.60$ & $0-0.1$ & $0-0.1$ & $0-0.1$ \\
\hline$P$-value & & 0.00 & 0.317 & 0.025 \\
\hline \multicolumn{5}{|l|}{ DCNVA $(40 \mathrm{~cm})$} \\
\hline Mean \pm SD & $0.078 \pm 0.113$ & $0.00 \pm 0.00$ & $0.00 \pm 0.00$ & $0.012 \pm 0.033$ \\
\hline \multirow[t]{2}{*}{ Range } & $0.00-0.30$ & $0.00-0.00$ & $0.00-0.00$ & $0.00-0.10$ \\
\hline & & 0.004 & 1.0 & 0.083 \\
\hline
\end{tabular}

Abbreviations: CDVA, corrected distance visual acuity; DCNVA, distance-corrected near visual acuity; SD, standard deviation; UDVA, uncorrected distance visual acuity; UNVA, uncorrected near visual acuity. 


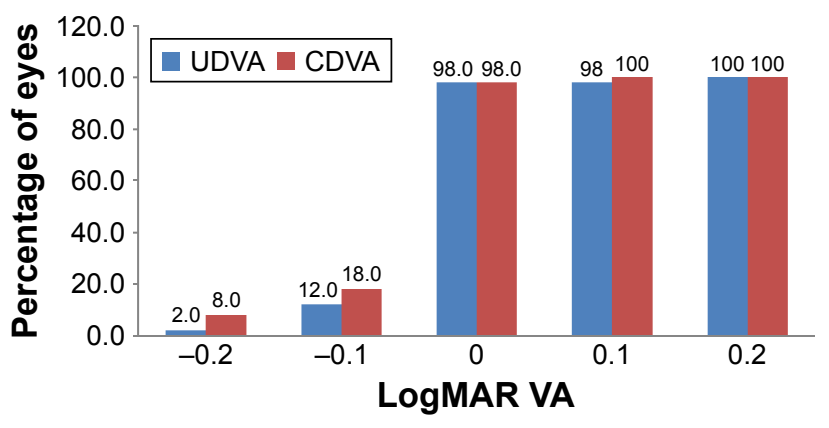

Figure I Cumulative bar graph for distance visual acuity at 12 months. Abbreviations: CDVA, corrected distance visual acuity; UDVA, uncorrected distance visual acuity.

\section{Binocular reading acuity and reading speeds at 70,80 , and $90 \mathrm{~cm}$}

Uncorrected and distance-corrected binocular reading acuity assessed at 1, 6, and 12 months showed best results at the distance of $80 \mathrm{~cm}$ compared with 70 and $90 \mathrm{~cm}$ at all visits. The differences were significant at 1-month follow-up, while at 6-month and 1-year follow-up, only the difference between reading acuity at 70 and $80 \mathrm{~cm}$ was found to be significant. Reading acuity improved over time, being best at 12 months, and this finding was statistically significant at 70 and $90 \mathrm{~cm}$ (Table 2). However, at 12 months through all distances, the range of uncorrected and distance-corrected visual acuity remained between $0.044 \pm 0.058$ to $0.09 \pm 0.072$ and $0.034 \pm 0.056$ to $0.069 \pm 0.084 \log$ MAR units, respectively. A similar trend was observed for the reading speeds, being best at $80 \mathrm{~cm}$ and improving over time. However, the changes were not statistically significant. At 6 months, there was a nonsignificant drop in both uncorrected reading acuity and reading speeds compared with 1 month for all distances which improved by 12 months.

\section{Defocus curves}

Figure 4 shows the binocular mean defocus curves under mesopic conditions. The best visual acuity results were obtained

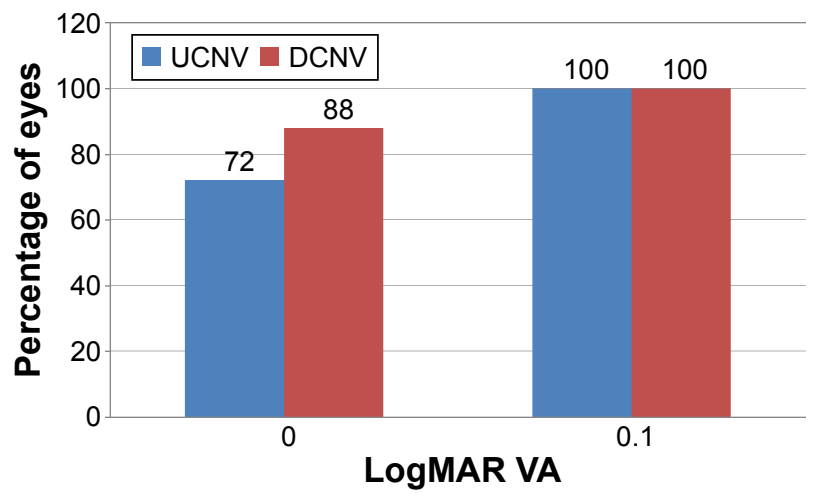

Figure 2 Cumulative bar graph for binocular near visual acuity at 12 months. Abbreviations: DCNV, distance corrected near vision; UCNV, uncorrected near vision.

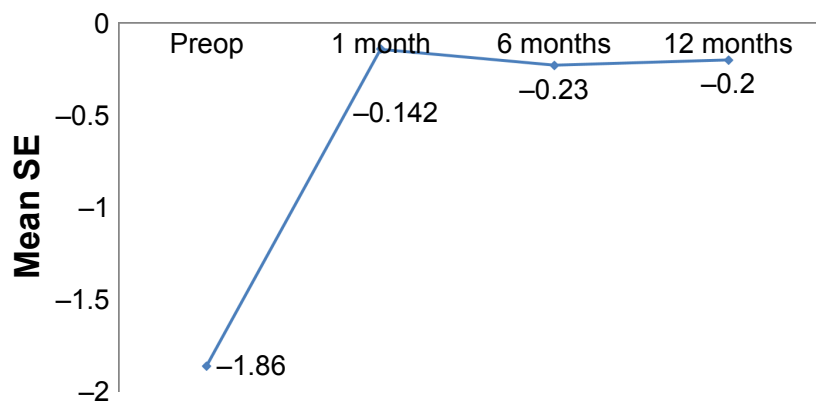

Figure 3 Stability of refraction over time. Abbreviation: SE, spherical equivalent.

at $0.00 \mathrm{D}$ defocus equivalent to distance vision. A second peak was observed at $-2.00 \mathrm{D}$, corresponding to good near vision. In the intermediate zone, no distinct peak was observed. However, in this interval, the curve was in the zone of $0.1 \log$ MAR or better visual acuity without a sharp drop which corresponds to useful vision at intermediate distance.

\section{Contrast sensitivity}

Figure 5 shows the binocular contrast sensitivity under mesopic conditions at 1 month, 6 months, and 12 months postoperatively.

Table 2 Reading acuity and reading speed over time

\begin{tabular}{|c|c|c|c|}
\hline SRD values & I month & 6 months & 12 months \\
\hline \multicolumn{4}{|l|}{$70 \mathrm{~cm}($ mean $\pm S D)$} \\
\hline UCRA & $0.12 \pm 0.07$ & $0.13 \pm 0.05$ & $0.09 \pm 0.072$ \\
\hline$P$-value & & 0.257 & 0.022 \\
\hline UCWPM & $145.6 \pm 61.9$ & $14 \mid .84 \pm 59.18$ & $153.68 \pm 54.05$ \\
\hline$P$-value & & 0.886 & 0.230 \\
\hline DCRA & $0.091 \pm 0.067$ & $0.093 \pm 0.079$ & $0.069 \pm 0.084$ \\
\hline$P$-value & & 0.722 & 0.169 \\
\hline CWPM & $|50.24 \pm 6| .76$ & $148.52 \pm 58.59$ & $|60.4 \pm 52|$. \\
\hline$P$-value & & 0.925 & 0.313 \\
\hline \multicolumn{4}{|l|}{$80 \mathrm{~cm}($ mean \pm SD $)$} \\
\hline UCRA & $0.058 \pm 0.045$ & $0.08 \pm 0.078$ & $0.044 \pm 0.058$ \\
\hline$P$-value & & 0.064 & 0.402 \\
\hline UCWPM & $155.6 \pm 55.23$ & $135.00 \pm 42.53$ & $169.0 \pm 74.85$ \\
\hline$P$-value & & 0.060 & 0.048 \\
\hline DCRA $($ mean $\pm S D)$ & $0.047 \pm 0.044$ & $0.05 \pm 0.065$ & $0.034 \pm 0.056$ \\
\hline$P$-value & & 0.154 & 0.652 \\
\hline CWPM & $160.3 \pm 55.34$ & $138.96 \pm 43.0$ & $|74.48 \pm 7| .97$ \\
\hline$P$-value & & 0.70 & 0.023 \\
\hline \multicolumn{4}{|l|}{$90 \mathrm{~cm}($ mean \pm SD $)$} \\
\hline UCRA (mean $\pm S D)$ & $0.08 \pm 0.066$ & $0.097 \pm 0.058$ & $0.065 \pm 0.035$ \\
\hline$P$-value & & 0.569 & 0.047 \\
\hline UCWPM & $|50.08 \pm 5| .76$ & $135.48 \pm 4 \mid .16$ & $154.4 \pm 52.8$ \\
\hline$P$-value & & 0.331 & 0.247 \\
\hline $\mathrm{DCRA}($ mean $\pm \mathrm{SD})$ & $0.062 \pm 0.066$ & $0.07 \pm 0.064$ & $0.042 \pm 0.039$ \\
\hline$P$-value & & 0.510 & 0.060 \\
\hline CWPM & $154.48 \pm 50.3$ & $138.84 \pm 39.76$ & $156.48 \pm 54.18$ \\
\hline$P$-value & & 0.319 & 0.242 \\
\hline
\end{tabular}

Abbreviations: CWPM, corrected words per minute; DCRA, distance-corrected reading acuity; IOL, intraocular lens; SD, standard deviation; SRD, Salzburg Reading Desk; UCRA, uncorrected reading acuity; WPM, words per minute; UCWPM, uncorrected words per minute; DCWPM, distance corrected words per minute; UCRS, uncorrected reading speeds. 


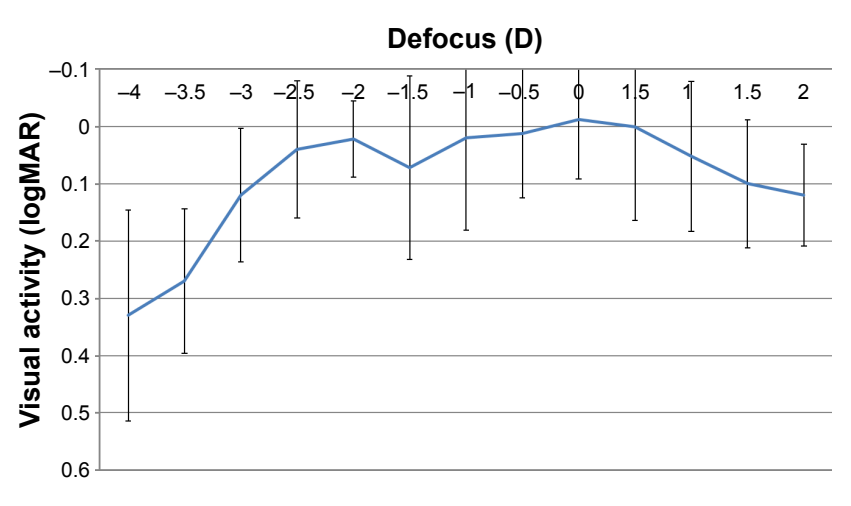

Figure 4 Binocular defocus curves under mesopic conditions.

At 6 months, slight reduction in contrast sensitivity was seen at higher spatial frequencies of 12 and $18 \mathrm{cpd}$; however, the difference was not statistically significant. At 12 months, the contrast sensitivity was comparable to 1-month values at all spatial frequencies $(P>0.05)$.

\section{Dysphotopic phenomena and spectacle independence evaluation}

Table 3 shows the mean dysphotopsia scores, which showed continuous improvement over time, being significantly lowest at 12 months $(P<0.05)$. One patient reported a score of 3 (considerable trouble) for halos and glare each at 1 month which reduced at 6 months to 2 and 1 , respectively. No patient reported a score of 4 (overwhelming trouble) for any visual symptoms evaluated. All patients reported $100 \%$ spectacle freedom for distance (watching television), intermediate (working on computer), and reading (Table 3 ).

\section{Long-term complications}

Five out of the total 50 eyes developed PCO, requiring YAG capsulotomy at a mean follow-up time of 6.7 months. Three eyes had visually significant PCO, warranting YAG capsulotomy. However, in the remaining two eyes, the main indication of YAG capsulotomy was not the mild PCO, but a significant drop in contrast sensitivity, while the visual

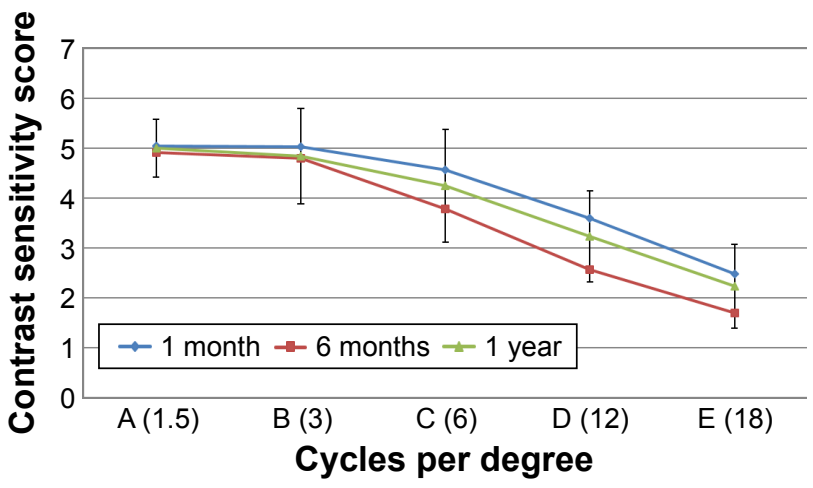

Figure 5 Contrast sensitivity over time.
Table 3 Patient satisfaction - dysphotopsia score and spectacle independence at I, 3, and 12 months postoperatively

\begin{tabular}{|c|c|c|c|}
\hline & I month & 2 months & 12 months \\
\hline Mean & $4.2 \pm 0.816$ & $2.2 \pm 0.645$ & $1.08 \pm 0.276$ \\
\hline $\begin{array}{l}\text { dysphotopsia } \\
\text { score } \pm \text { SD }\end{array}$ & $\begin{array}{l}\text { Distant vision } \\
\text { (television) }\end{array}$ & $\begin{array}{l}\text { Intermediate } \\
\text { vision (computer) }\end{array}$ & $\begin{array}{l}\text { Near vision } \\
\text { (reading) }\end{array}$ \\
\hline $\begin{array}{l}\text { Spectacle } \\
\text { independence }\end{array}$ & $100 \%$ & $100 \%$ & $100 \%$ \\
\hline
\end{tabular}

Abbreviation: SD, standard deviation.

acuity in these eyes did not significantly change, compared to 1-month values. Apart from PCO, no other visually significant complications such as cystoid macular edema, post op uveitis, or glaucoma occurred in any of the study eyes at the end of 12 months.

\section{Discussion}

Visual and refractive outcomes of AT LISA trifocal IOLs have been evaluated in various studies. These IOLs provide three main foci in order to improve intermediate vision. ${ }^{14,15}$ Recently, Mojzis et al evaluated 1-year outcomes with AT LISA trifocal IOLs. ${ }^{11}$ In their study, from 1 to 12 months, significant changes were observed in sphere showing slight but statistically significant hyperopic shift over time. In contrast, slight myopic shift of SE over time was observed; however, it was not statistically significant. These changes may also be explained by changes in effective lens position due to capsular contraction. ${ }^{16}$

Posterior capsular opacification rate was similar in both studies (Mojzis et al $-15.8 \%$ and present study $-16 \%$ ); however, the YAG capsulotomy rate in the present study was much higher (10\% vs $3.3 \%)$. The possible reason could be that some patients required early YAG capsulotomy due to reduction in contrast, although the PCO was not clinically significant.

In their study, they did not find significant differences for intermediate visual acuity between 66 and $80 \mathrm{~cm}$; however, in this study, reading acuity was significantly better at $80 \mathrm{~cm}$ compared with 70 and $90 \mathrm{~cm} .{ }^{11}$ These differences could be explained by the fact that in the present study, reading acuity was assessed with SRD, which is proposed to be a more realistic method compared with the conventional Early Treatment Diabetic Retinopathy study charts as used in their study. ${ }^{17}$

Previously, this instrument has been used to compare bilateral reading performance within the first 6 months after implantation of four IOL models. ${ }^{18,19}$ It was found that multifocal IOLs with a diffractive component provided a comparable reading performance that was significantly better than the one obtained with refractive multifocal and monofocal IOLs. Although the visual and refractive outcomes of 
AT LISA tri 839MP IOL have been compared with other trifocal IOLs, the functional vision and reading speeds between the two models were not compared. ${ }^{20}$

Intermediate visual acuity was not recorded using the conventional charts since they assess reading visual acuity only, which is a limited predictor of performance of real-world tasks. This was the reason leading to the development of reading performance, based on tests such as SRD, which are designed to simultaneously measure reading acuity and speed.

Attia et al recently evaluated reading acuity and reading speeds with the Physiol Fine vision trifocal IOL using the SRD. ${ }^{21}$ In their study, binocular uncorrected reading acuity and reading speed at $80 \mathrm{~cm}$ was $0.11 \log$ MAR and $98 \mathrm{wpm}$, respectively, whereas in the present study both the reading acuity and reading speed at $80 \mathrm{~cm}$ showed better results (reading acuity $0.044 \log$ MAR and reading speed $169 \mathrm{wpm}$ ). However, they also evaluated reading acuity and speed at preferred distances and found the preferred distance at $64 \mathrm{~cm}$. In this study, reading speeds and acuity at $70 \mathrm{~cm}$ are comparable to their preferred distance; however, best results were obtained at $80 \mathrm{~cm}$. This may be attributed to differences in design of the IOLs and difference in the light distribution at near intermediate and distance and variation in amount of near addition. Also, the sample size in their study was 11 patients in contrast to the present study ( 25 patients), leading to variability in the interpretation of statistical results.

This study did not evaluate reading acuity and speed at preferred distances, which may be a potential limitation of this study. However, Attia et al did not evaluate the effect of PCO and incidence of YAG in their study, which had a mean follow-up of 15.77 months. Occurrence of PCO may affect the reading performance as observed in our study, where reading performance improved after YAG capsulotomy. Mild, nonsignificant drop in the reading acuity, reading speeds, and contrast sensitivity scores was observed at all distances at a mean follow-up period of 6 months, which were attributed to the development of mild PCO. However, after YAG capsulotomy, all eyes showed improvement in these parameters and subjective symptoms at the end of 1-year follow-up. Improvement in the maximum corrected reading acuity and reading speed with time was also observed, both being highest at the end of 12 months. This can partially be attributed to neural adaptation to the multiple foci generated by the trifocal IOL and the learning curve effect that occurs when patients take the same test again.

At 1 year, all patients achieved excellent reading acuities and reading speeds at 70,80 , and $90 \mathrm{~cm}$ corresponding to the usual intermediate distances. These parameters at 70,80 , and
$90 \mathrm{~cm}$ distances to account for most of the intermediate range activities were evaluated, such as working on computer, in the kitchen, and other household tasks, and also inter-person differences in body height and arm length. The uncorrected reading function was best at $80 \mathrm{~cm}$; however, it was 0.09 to $0.04 \log$ MAR units for 70 and $90 \mathrm{~cm}$, suggesting the excellent performance of the IOL over complete range of intermediate distance. These findings support the claim of better intermediate visual performance with diffractive-based trifocal IOLs. ${ }^{19}$

One potential limitation of the study could be that the pupil size before and after the surgery was not measured while performing postoperative tests. However, pupil size has a direct influence on the outcomes with full-refractive IOLs. ${ }^{5,6}$ AT LISA TRI being a diffractive and pupil independent IOL provided excellent outcomes across all range of distances in the current study. ${ }^{14}$

\section{Conclusion}

The AT LISA trifocal IOLs seemed to provide excellent distance, intermediate, and very good near vision in the longterm follow-up. Yag capsulotomy for early PCO and drop in contrast sensitivity did not seem to have affected visual outcomes significantly. Standardized measurement of reading performance by using the SRD allowed more realistic and practical assessment of patient's acceptance to trifocal IOL implantation after cataract surgery.

\section{Disclosure}

This investigator led study was partly supported by Carl Zeiss Meditec AG, ZEISS Group. The authors report no other conflicts of interest in this work.

\section{References}

1. Alio JL, Montalban R, Pena-Garcia P, Soria FA, Vega-Estrada A. Visual outcomes of a trifocal aspheric diffractive intraocular lens with microincision cataract surgery. J Refract Surg. 2013;29(11): 756-761.

2. Voskresenskaya A, Pozdeyeva N, Pashtaev N, Batkov Y, Treushnicov V, Cherednik V. Initial results of trifocal diffractive IOL implantation. Graefes Arch Clin Exp Ophthalmol. 2010;248(9):1299-1306.

3. Javitt JC, Steinert RF. Cataract extraction with multifocal intraocular lens implantation: a multinational clinical trial evaluating clinical, functional, and quality-of-life outcomes. Ophthalmology. 2000;107(11): 2040-2048.

4. Javitt J, Brauweiler HP, Jacobi KW, et al. Cataract extraction with multifocal intraocular lens implantation: clinical, functional, and quality-of-life outcomes. Multicenter clinical trial in Germany and Austria. J Cataract Refract Surg. 2000;26(9):1356-1366.

5. Salati C, Salvetat ML, Zeppieri M, Brusini P. Pupil size influence on the intraocular performance of the multifocal AMO-array intraocular lens in elderly patients. Eur J Ophthalmol. 2007;17(4):571-578.

6. Artigas JM, Menezo JL, Peris C, Felipe A, Díaz-Llopis M. Image quality with multifocal intraocular lenses and the effect of pupil size. JCataract Refract Surg. 2007;33(12):2111-2117. 
7. Maxwell WA, Lane SS, Zhou F. Performance of presbyopia-correcting intraocular lenses in distance optical bench tests. J Cataract Refract Surg. 2009;35(1):166-171.

8. Mesci C, Erbil H, Ozdoker L, Karakurt Y, Bilge AD. Visual acuity and contrast sensitivity function after accommodative and multifocal intraocular lens implantation. Eur J Ophthalmol. 2010;20(1):90-100.

9. Gatinel D, Houbrechts Y. Comparison of bifocal and trifocal diffractive and refractive intraocular lenses using an optical bench. J Cataract Refract Surg. 2013;39(7):1093-1099.

10. Jonker SMR, Bauer NJC, Makhotkina NY, Berendschot TTJM, van den Biggelaar FJHM, Nuijts RMMA. Comparison of a trifocal intraocular lens with a +3.0 D bifocal IOL: results of a prospective randomized clinical trial. J Cataract Refract Surg. 2015;41(8):1631-1640.

11. Mojzis P, Majerova K, Hrckova L, Pinero DP. Implantation of a diffractive trifocal intraocular lens: one-year follow-up. J Cataract Refract Surg. 2015;41:1623-1630.

12. Donoso R, Mura JJ, Lopez M, Papic A. [Emmetropization at cataract surgery. Looking for the best IOL power calculation formula according to the eye length]. Arch Soc Esp Oftalmol. 2003;78(9):477-480. Spanish.

13. Ghanem AA, El-Sayed HM. Accuracy of intraocular lens power calculation in high myopia. Oman J Ophthalmol. 2010;3(3):126-130.

14. Gatinel D, Pagnoulle C, Houbrechts Y, Gobin L. Design and qualification of a diffractive trifocal optical profile for intraocular lenses J Cataract Refract Surg. 2011;37(11):2060-2067.
15. Madrid-Costa D, Ruiz-Alcocer J, Ferrer-Blasco T, Garcia-Lazaro S, Montes-Mico R. Optical quality differences between three multifocal intraocular lenses: bifocal low add, bifocal moderate add, and trifocal. $J$ Refract Surg. 2013;29(11):749-754.

16. Nanavaty NA, Raj SM, Vasavada VA, Vasavada A, Vasavada AR. Anterior capsule cover and axial movement of intraocular lens. Eye. 2008;22:1015-1023.

17. Dexl AK, Schlögel H, Wolfbauer M, Grabner G. Device for improving quantification of reading acuity and reading speed. J Refract Surg. 2010;26:682-688.

18. Rasp M, Bachernegg A, Seyeddain O, et al. Bilateral reading performance of 4 multifocal intraocular lens models and a monofocal intraocular lens under bright lighting conditions. J Cataract Refract Surg. 2012;38(11):1950-1961.

19. Alio JL, Grabner G, Plaza-Puche AB, et al. Postoperative bilateral reading performance with 4 intraocular lens models: six-month results. $J$ Cataract Refract Surg. 2011;37(5):842-852.

20. Marques EF, Ferreira TB. Comparison of visual outcomes of 2 diffractive trifocal intraocular lenses. J Cataract Refract Surg. 2015;41(2):354-363.

21. Attia MS, Auffarth GU, Khoramnia R, Linz K, Kretz FT. Near and intermediate reading performance of a diffractive trifocal intraocular lens using a reading desk. J Cataract Refract Surg. 2015;41:2707-2714.
Clinical Ophthalmology

\section{Publish your work in this journal}

Clinical Ophthalmology is an international, peer-reviewed journal covering all subspecialties within ophthalmology. Key topics include: Optometry; Visual science; Pharmacology and drug therapy in eye diseases; Basic Sciences; Primary and Secondary eye care; Patient Safety and Quality of Care Improvements. This journal is indexed on

Submit your manuscript here: http://www.dovepress.com/clinical-ophthalmology-journal

\section{Dovepress}

PubMed Central and CAS, and is the official journal of The Society of Clinical Ophthalmology (SCO). The manuscript management system is completely online and includes a very quick and fair peer-review system, which is all easy to use. Visit http://www.dovepress.com/ testimonials.php to read real quotes from published authors. 